\title{
The Origin of the Myofibroblasts in Breast Cancer \\ Recapitulation of Tumor Environment in Culture Unravels Diversity and Implicates Converted Fibroblasts and Recruited Smooth Muscle Cells
}

\author{
Lone Rónnov-Jessen, ${ }^{\star}$ Ole W. Petersen, ${ }^{\star \star}$ Victor E. Koteliansky, ${ }^{\mathbf{f}}$ and Mina J. Bissell ${ }^{\$ \ddagger}$ \\ * Structural Cell Biology Unit, Institute of Medical Anatomy, the Panum Institute, DK-2200 Copenhagen N, and Department of Tumor \\ Endocrinology, Division for Cancer Biology, Danish Cancer Society, DK-2100 Copenhagen O, Denmark; ${ }^{\ddagger}$ Division of Life Sciences, \\ Lawrence Berkeley Laboratory, University of California, Berkeley, California 94720; and ${ }^{8}$ Laboratoire du Physiopathologie du \\ Developpement, CNRS URA 1337 and École Normale Superieure, 75230 Paris Cedex 05, France
}

\begin{abstract}
The origin of myofibroblasts in stromal reaction has been a subject of controversy. To address this question definitively, we developed techniques for purification and characterization of major stromal cell types. We defined a panel of markers that could, in combination, unequivocally distinguish these cell types by immunocytochemistry, iso-electric focusing, immunoblotting, and two-dimensional gel electrophoresis. We then devised an assay to recapitulate in culture, within two weeks of incubation, critical aspects of the microenvironment in vivo including the typical tissue histology and stromal reaction. When confronted with tumor cells in this assay, fibroblasts readily converted into a graded pattern of myogenic differentiation, strongest in the immediate vicinity of tumor cells. Vascular smooth muscle cells (VSMC), in contrast, did not change appreciably and remained coordinately smooth muscle differentiated. Midcapillary pericytes showed only a slight propensity for myogenic differentiation. Analysis of ten primary tumors implicated converted fibroblasts $(10 / 10)$, vascular smooth muscle cells $(4 / 10)$, and pericytes $(1 / 10)$ in the stromal reaction. Tumor cells were shown to specifically denude the venules both in culture and in vivo, explaining the VSMC phenotype in the stroma. The establishment of this assay and clarification of the origin of these cells pave the way for further analysis of the mechanisms of conversion, and of the consequence of such heterogeneity for diagnosis and treatment. (J. Clin. Invest. 1995. 95:859-873.) Key words: tumor modeling • microenvironment - stromal reaction - stromal/epithelial interactions • extracellular matrix

\section{Introduction}

Induction of molecular features of a vascular smooth muscle cell (VSMC) ${ }^{1}$ phenotype as a universal interstitial cell response

Address correspondence to Dr. Mina J. Bissell, Director, Division of Life Sciences, Lawrence Berkeley Laboratory, 1 Cyclotron Road, Building 83-101, Berkeley, CA 94720. Phone: 510-486-4365; FAX: 510486-5586.

Received for publication 11 July 1994.

1. Abbreviations used in this paper: 2-D, two-dimensional; $\alpha$-sm actin, $\alpha$-smooth muscle actin; DME-F12, Dulbecco's modified Eagle's medium-Ham's F12; ECM, extracellular matrix; HLA-DQ, human lymphocyte antigen-DQ; IEF, isoelectric focusing; sm-myosin, smooth muscle myosin heavy chain; VSMC, vascular smooth muscle cell.

J. Clin. Invest.

(C) The American Society for Clinical Investigation, Inc.

$0021-9738 / 95 / 02 / 0859 / 15 \quad \$ 2.00$

Volume 95, February 1995, 859-873 to any pertubation of tissue homeostasis such as injury, radiation, and epithelial neoplasia is a subject that has attracted much attention recently (1-16). Myofibroblasts, the interstitial cells of unknown origin, are particularly frequent in the stroma of breast neoplasia $(2,3,13,16)$. The expression of smooth muscle-specific proteins includes $\alpha$-smooth muscle actin ( $\alpha$-sm actin), calponin and smooth muscle-myosin heavy chain (smmyosin $)(2,3,16)$. Fibroblasts appear to be an obvious candidate for such conversion (11-14). On the other hand, the striking similarity of myofibroblasts with true VSMCs and pericytes has led to speculations that myofibroblasts may originate from the vascular bed $(2,5,17-19)$. In the case of breast, this hypothesis would be compatible with the high level of angiogenesis which arises from small venules $(20,21)$ : at an early stage, mural cells are carried along with the endothelial sprouting (22). A vascular origin of myofibroblasts would imply that the VSMCs migrated from the blood vessel basement membrane and left the vascular bed in favor of the interstitial collagenous stroma. In this regard, it has been shown that VSMCs which migrate into the intima of aorta in fact change into the synthetic phenotype, i.e., they partly down-regulate their smooth muscle phenotype $(23,24)$. Thus, partial loss of differentiated functions of VSMCs may lead to the same end result as activation of non-muscle fibroblasts - the level of myo-differentiation being the only detectable difference. Theoretically, myoepithelial cells could also give rise to myofibroblasts if they were able to down-regulate their keratins.

It is essential to experimentally analyze the ability of resident fibroblasts, pericytes, VSMCs, and myoepithelial cells to undergo such transitions. However, studies of myofibroblasts have been hindered by problems with both purification of candidate precursor cells, and lack of culture models providing the accurate microenvironment of peritumoral stromal cells. Here, we describe a new approach by which we overcame these problems and were able to study the response of each of the cell types to tumor cells under well-controlled experimental conditions. We have developed techniques for isolation and characterization of nearly pure populations of fibroblasts, pericytes, VSMCs, and myoepithelial cells, and have developed markers for their identification.

Focusing on $\alpha$-sm actin, calponin and sm-myosin, we confronted each of the three cell types with tumor cells in an organotypic assay and compared their response with that obtained in vivo with the aim of learning which cells will recapitulate the myofibroblast phenotype in this physiological setting. We believe that the evidence makes a compelling case for a scenario where myofibroblasts originate from fibroblasts $>$ VSMCs $>>$ pericytes. The latter phenotype is very subtle and may not fit within the conventional perception of myofi- 
broblasts. The availability of this model system and well-defined stromal populations will allow the investigation of the mechanisms by which the tumor cells convert these cells, and of the underlying reasons for the heterogeneity. These studies may also shed light on the factors that regulate the differentiated state of smooth-muscle characteristics in general.

\section{Methods}

Cell isolation. Stromal cells from a total of 50 different breast tissue samples were used in this study. Briefly, the tissue was minced immediately after excision in Dulbecco's modified Eagle's medium-Ham's F12 (DME-F12) supplemented with $50 \mu \mathrm{g} / \mathrm{ml}$ gentamicin (Garamycin, Schering, Kenilworth, NJ) and $2 \mathrm{mM}$ glutamine (Sigma Chemical Co., St. Louis, MO) into fragments of $\sim 2 \mathrm{~mm}^{3}$. The tissue was then collagenase-digested at $37^{\circ} \mathrm{C}$ for $24 \mathrm{~h}$ on a rotary shaker at $70 \mathrm{rpm}$ in $6 \mathrm{ml}$ of DME-F12 containing $900 \mathrm{IU} / \mathrm{ml}$ collagenase (CLS III; Worthington Biochemical Corp., Freehold, NJ).

Blood vessels and fibroblasts were isolated by differential centrifugation of the collagenase digest (11). Fibroblasts were obtained by three centrifugations. First, blood vessels and epithelial organoids were pelleted by $175 \mathrm{~g}$. Next, the supernatant comprising smaller blood vessels and fibroblasts was centrifuged for $5 \mathrm{~min}$ at $125 \mathrm{~g}$, leaving the fibroblasts in the supernatant. These were finally pelleted at $500 \mathrm{~g}$ for $10 \mathrm{~min}$. The pellet was resuspended in DME-F12 and plated in DMEF12 on T-25 flasks (Primaria ${ }^{\mathrm{TM}}$, Falcon No. 3813; Becton-Dickenson, Albertslund, Denmark) or for some experiments, plated on DME-F12 supplemented with $20 \%$ fetal calf serum (FCS) for $24 \mathrm{~h}$ followed by serum-free DME-F1 2 for $3 \mathrm{~d}$ before co-cultivation. In other experiments, fibroblasts were used after permanent cultivation in DME-F12 and 20\% FCS on collagen coated ( $8 \mu \mathrm{g} / \mathrm{cm}^{2}$ of Vitrogen 100; Collagen Corporation, Palo Alto, CA purchased from In Vitro, Copenhagen, Denmark) T-25 flasks (Nunc, Roskilde, Denmark).

Blood vessels in the first pellet were separated from epithelial organoids by resuspension of the pellet in $10 \mathrm{ml}$ of medium. The epithelial organoids settled first, leaving the blood vessels in the supernatant. After further purification, the blood vessels were either rotated in DME-F12 for $24 \mathrm{~h}$ to wash out residual collagenase before incorporation into gels (see below) or they were mildly trypsinized to release the perivascular coat of fibroblasts (12) before centrifugation and further trypsination into single cells and plating on collagen coated flasks in DME-F12 with 20\% FCS.

Purified epithelial organoids were resuspended in DME-F12 and rotated for another $24 \mathrm{~h}$ to detach the pre- and postcapillary arterioles and venules from terminal duct lobular units (TDLU) and interlobular ducts, respectively. The pre- and postcapillaries still attached were released by repeated resuspension. The purified fraction of TDLU and interlobular ducts were aspirated through a 27 -gauge needle which resulted in fragmentation of TDLU and interlobular ducts and release of pericytes from midcapillary endothelial tubes. After a few seconds of settlement, the supernatant comprising capillaries, stripped endothelial tubes, and pericytes was centrifuged $2.5 \mathrm{~min}$ at $125 \mathrm{~g}$. The supernatant from this centrifugation contained pericytes only. As an additional source of pericytes, we used an extended pericyte cell line generated from a focal outgrowth of cells in cultures of breast microvasculature (Rønnov-Jessen, L., O. W. Petersen, and M. J. Bissell, manuscript in preparation ). All pericytes were cultured under the same conditions as fibroblasts and VSMCs, i.e., DMEF12 supplemented with $20 \%$ FCS on collagen coated flasks. As a control for stromal cells in co-culture experiments, we used normal breast myoepithelial cells, isolated as previously described (25) and cultured on $20 \%$ FCS. For two-dimensional (2-D) gel electrophoresis epithelial cells were initially expanded on serum-free medium (CDM4) $(25,26)$, followed by the same medium as used for stromal cells for $3 \mathrm{~d}$ before ${ }^{35} \mathrm{~S}$-methionine incorporation (see below).

Immunocytochemistry. For immunoperoxidase cytochemistry on cultured cells or $5 \mu \mathrm{m}$ cryosections of tissue ( 10 randomly selected primary breast tumors with myogenic stroma and two normal breast specimens) or gels (see below), the following monoclonal antibodies $(\mathrm{mAb})$ were used against: $\alpha$-smooth muscle actin (1A4, Sigma Chemical Co.), sm-myosin (kindly provided by Dr. M. A. Glukhova), calponin (27), $\alpha 1$-integrin (TS2/7, T Cell Sciences, Cambridge, CA), vimentin (VIMS, Medac), laminin (M638, Dako, Glostrup, Denmark), tenascin (M636, Dako), a cytoskeleton-associated antigen in myoepithelial cells (BG3C8 kindly provided by professor J. E. Celis, University of Aarhus, Denmark) (28), human lymphocyte antigen-DQ (HLA-DQ, Leu-10; Becton Dickenson, Alberto, Denmark), factor VIII-related antigen in endothelial cells (F8, AMD, Artarmon, Australia) and high molecular weight-melanoma-associated antigen (HMW-MAA) identical to chondroitin sulfate (MON 7004; IgG1, Monosan, Am Uden, The Netherlands). Rabbit anti-mouse immunoglobulins (Z259; Dako) were used as secondary antibody, peroxidase mouse anti-peroxidase (P850, Dako) as tertiary antibody and 3,3-diaminobenzidine with freshly added $\mathrm{H}_{2} \mathrm{O}_{2}$ was used for the peroxidase reaction (25).

For double- and triple-labeling immunofluorescence cytochemistry, cryosections were incubated with the following primary mAbs: endothelial surface antigen (PAL-E; IgG2a, Monosan) (29) or $\alpha$-sm actin (1 A4; IgG2a) combined with sm-myosin (IgG1), and keratin $\mathrm{K} 18$ in tumor cells (Ks 18.8; IgM, Biotest, Dreieich, Germany) or $\alpha 1$-integrin in stromal cells (IgG1). In the second sequence, goat anti-mouse IgG2aTexas red (1080-07, Southern Biotechnology, Birmingham, AL) or goat anti-mouse IgG1-FITC (1070-02, Southern Biotechnology) were used. For triple labeling, three sequences were necessary with goat antimouse IgM conjugated to biotin (1020-08, Southern Biotechnology) in the second sequence followed by incubation with 7-amino-4-methylcoumarin-3-acetic acid-streptavidin (STAR 61; Serotec Ltd., Oxford, England). All slides were mounted in $20 \mu 1$ Fluoromount $\mathrm{G}$ ( 100 , Southern Biotechnology) containing $2.5 \mathrm{mg} / \mathrm{ml} \mathrm{n}$-propylgallate (Sigma Chemical Co.) (12)

Isoelectric focusing (IEF), sodium dodecyl sulfate polyacrylamide gel electrophoresis (SDS-PAGE), immunoblotting, and 2-D gel electrophoresis. Cells were trypsinized, quantified, and divided into two portions: one was used for protein determination and the other for IEF or SDS gels. Cell lysis, protein determination, IEF and immunoblotting with an antibody against all actins (A1804, Sigma Chemical Co.) were performed as previously described (14). For SDS gels, cells were lysed in Laemmli buffer and run at 10\% separation gels and 5\% stacking gels as described elsewhere (30). Immunoblotting of SDS gels were performed as for the IEF gels (12). 2-D gel electrophoresis was performed with cells lysed after $3 \mathrm{~d}$ in primary culture on $20 \%$ FCS according to the procedure described by Celis et al. $(14,31)$, the only modification being the use of $3.3 \%$ carrier ampholyte, $\mathrm{pH} 4-6$ (BioRad, Denmark) and pH 5-7 (Serva Feinbiochemica, purchased from Bie \& Berntsen, Rødovre, Denmark) in a 1:1 ratio. Also, fluorography was made essentially as described by Celis et al. $(14,31)$. Only, $5 \times 10^{5}$ counts were added per gel, and they were immersed in Amplify ${ }^{\mathrm{TM}}$ (Amersham, Birkerød, Denmark).

The tumor environment assay. Collagen gels $(2 \mathrm{ml})$ with a final concentration of $2.04 \mathrm{mg} / \mathrm{ml}$ were prepared in six-well dishes as previously described (13). Purified normal fibroblasts, VSMCs, or pericytes $\left(5 \times 10^{5}-1 \times 10^{6}\right)$ were co-cultured with $5 \times 10^{5}$ of either MCF-7 (including subline 9 for serum-free experiments) or HMT-3909 S13 malignant breast epithelial cells available for both serum-supplemented and serum-free conditions $(14,32,33)$. As a rule, the cocultures were kept for $14 \mathrm{~d}$ in collagen gels without release from the culture dish (as anchored gels) either in DME-F12 alone or in minimum essential medium with 5\% FCS (13). Specifically, in experiments with blood vessel organoids HMT-3909 cells were used in serum-free medium to prevent spontaneous recruitment of VSMCs as elicited by serum. In one type of control experiment, the incubation time was extended to six weeks and a concentric plastic ring was placed in the center of the well to allow anchored contraction to reach a maximum without stress relaxation (34). In another type of control experiment, the extracellular matrix was modified by co-gelifying Engelbrecht-Swarm-Holm basement membrane matrix (35) at either $10 \%$ or $50 \%$ with the collagen gels. In a final set of control experiments to test the maximal myogenic 

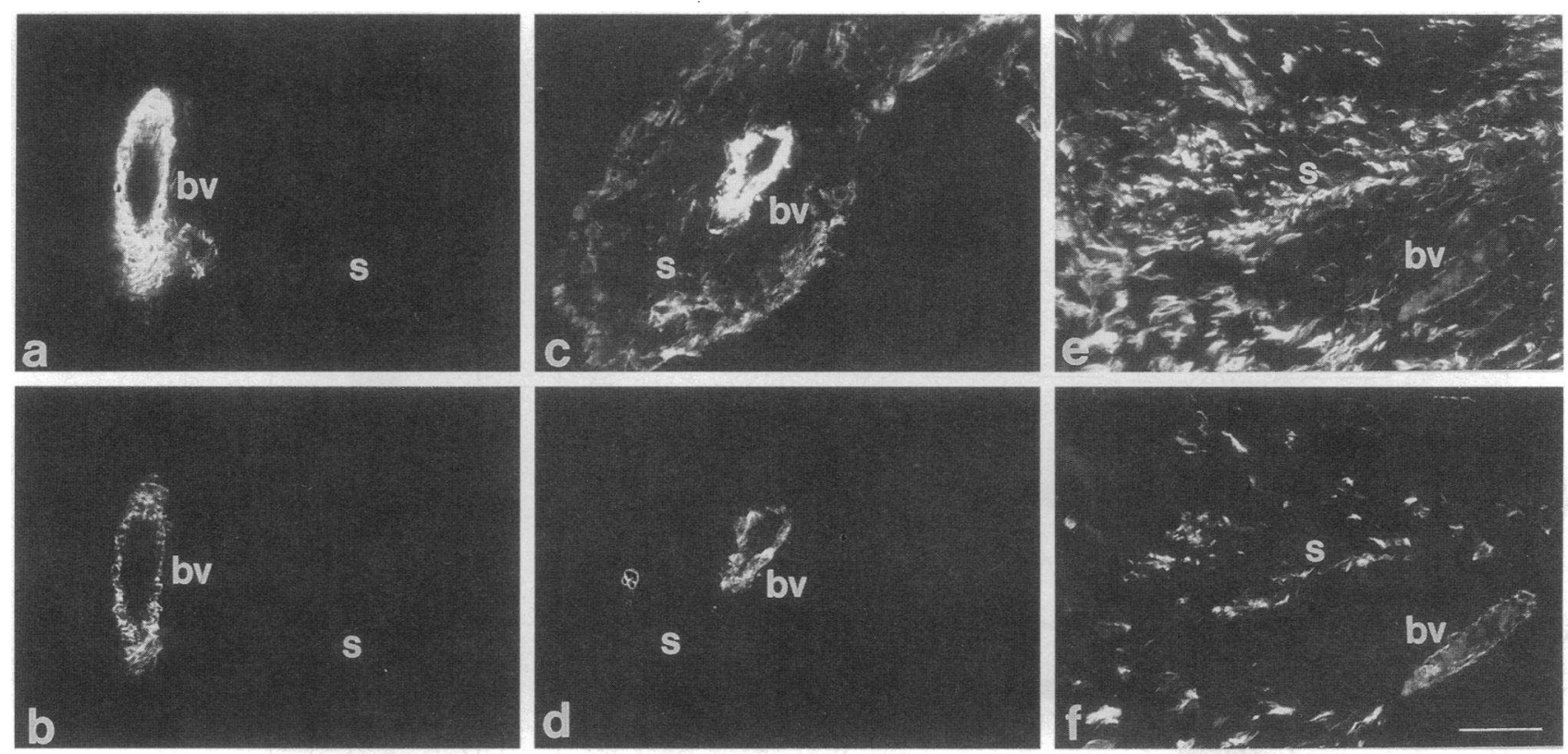

Figure 1. Interstitial stromal cells of normal and tumor tissue differ by levels of smooth muscle differentiation. Cryosections were double stained by immunofluorescence using mAbs specific for $\alpha$-sm actin $(a, c$, and $e)$ and sm-myosin $(b, d$, and $f)$. Whereas normal interstitial stroma ( $s ; a$ and $b$ ) was completely negative in terms of smooth muscle differentiation, (compare with positive staining in blood vessels; $b v$ ), tumor tissues ( $c$, $d, e$, and $f$ ) were almost always positive at least for $\alpha$-sm actin. ( $c$ and $d$ ) In this tumor, the stroma ( $s$ ) is positive for $\alpha$-sm actin but negative for sm-myosin. ( $e$ and $f$ ) In this tumor, the stromal reaction $(s)$ is very strong and some stromal cells are positive also for sm-myosin. These latter cells were negative for keratin and hence are not myoepithelial cells. Note a strong, consistent staining in blood vessels $(b v) . \times 180 ;$ bar, $50 \mu \mathrm{m}$.

effect of tumor cells on fibroblasts, incubation was extended to 8 wk or fibroblasts were incubated simultaneously with both tumor cell lines. The medium was changed every second day and the cultures were kept at $37^{\circ} \mathrm{C}$ in a humidified atmosphere of $75 \% \mathrm{~N}_{2}, 20 \% \mathrm{O}_{2}$ and $5 \% \mathrm{CO}_{2}$.

\section{Results}

In the normal breast, the interstitial fibroblasts are devoid of $\alpha$ sm actin and sm-myosin, the expression in the stroma being limited to VSMCs (Fig. 1, $a$ and $b$ ). It has been shown previously that $\alpha$-sm actin and sm-myosin are expressed in peritumoral stromal cells of breast carcinomas in vivo $(1-3,13,16)$. In some carcinomas, almost all interstitial cells express $\alpha$-sm actin (Fig. $1 c$ ), while sm-myosin is restricted to VSMCs (Fig. $1 d$ ); in other carcinomas $\alpha$-sm actin and sm-myosin are expressed in the same cells (Fig. 1, $e$ and $f$ ). A search for the cellular source of this response has focused on interstitial fibroblasts, VSMCs and pericytes. In order to decipher which cells are involved and which markers could delineate the developmental history, we must have clear markers and reasonably pure cell populations.

Isolation and characterization of fibroblasts, VSMCs, and pericytes. To isolate the individual stromal cell populations from breast tissue, we first defined the mural cells of the microvascular bed by immunostaining with three myogenic markers: $\alpha$-sm actin, calponin and sm-myosin (Fig. $2 A$ ). These were selected because of their broad reactivity with both venous and arterial VSMCs compared with, for example, desmin and caldesmon, which almost exclusively decorated arterial smooth muscle cells (not shown). Midcapillary pericytes were found to have no intrinsic smooth muscle differentiation similar to what has been reported for pericytes of other microvascular beds $(37,38,39)$.
They were, however, characterized by the simultaneous expression of $\alpha 1$-integrin and chondroitin sulfate (Fig. $2 A$ ) (40). The phenotype of midcapillary pericytes was confirmed by immunofluorescence cytochemistry on whole-mounts of breast acini and ducts, where the entire vascular bed was exposed for analysis (data not shown). This technique, as developed by Nehls and Drenckhahn (37), has proven indispensable in pericyte identification in situ.

Fibroblasts were released as single cells after tissue disaggregation leading to cultures that were generally $>95 \%$ pure (Fig. 2 B; Table I) (14). Under these culture conditions, they had no intrinsic smooth muscle differentiation - as is the case in vivo (Fig. 2, $B$ and $C$ ). VSMCs represented a mixture of cells purified from muscular arteries, arterioles, and small veins and venules, and initially were contaminated with $\sim 20 \%$ endothelial cells and were generally $>75 \%$ pure (Table I). The contaminating cells disappeared upon passaging. VSMCs showed a high degree of intrinsic smooth muscle differentiation (Fig. 2, $B$ and $C$ ). Midcapillary pericytes were quite different in morphology from both VSMCs and fibroblasts. The pericyte cultures used were either primary cultures ( $>65 \%$ pure) or cell lines (85\% pure; Fig. 2, $B$ and $C$; Table I; Rønnov-Jessen, L., M. J. Bissell, and O. W. Petersen, manuscript in preparation). Midcapillary pericytes were recognized distinctly by a strong staining for both a chondroitin sulfate and $\alpha 1$-integrin and lack of smooth muscle differentiation. Some staining for chondroitin sulfate was also seen in VSMCs of presumptive arterial origin, but these cells could be easily distinguished from pericytes because they were strongly positive for $\alpha$-sm actin (Fig. $2 B)(22,40)$. 
A

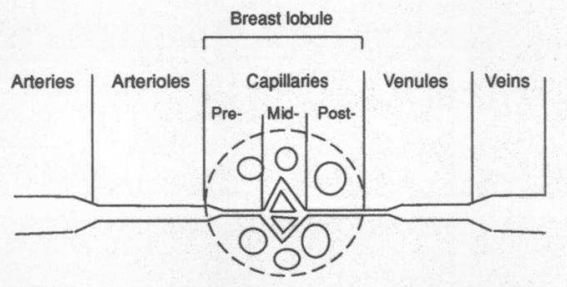

Resident
fibroblasts

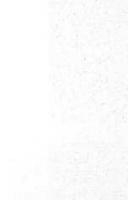

$\alpha-S m o o t h$
muscle actin

Calponin

Smooth

muscle myosin

a1-Integrin

Chondroitin
sulfate
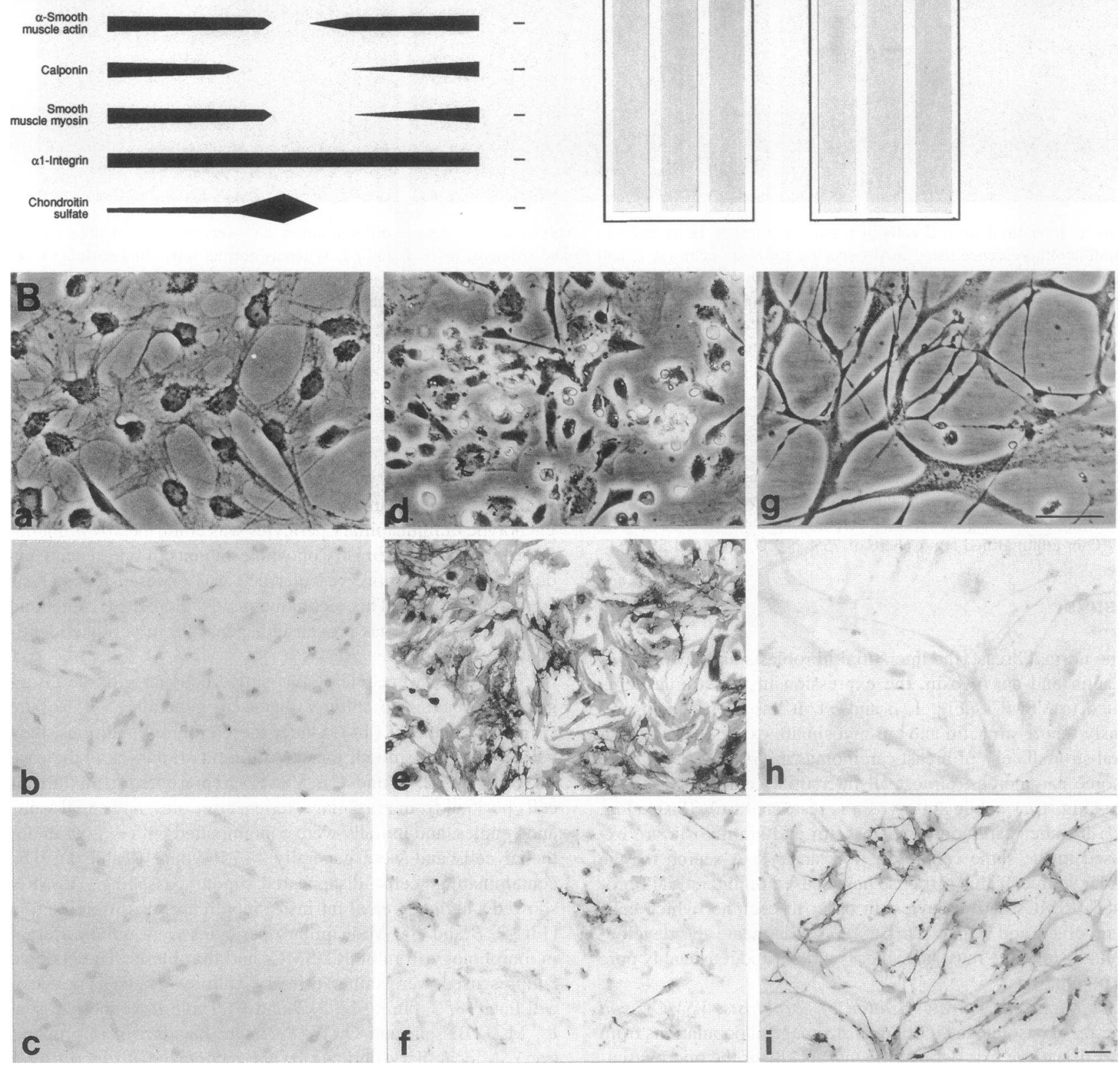

Figure 2. Characterization of purified stromal cell populations from normal breast. ( $A$ ) Schematic illustration of the distribution of myogenic markers in normal breast microvasculature and fibroblasts as obtained by immunoperoxidase stained cryostat sections. Note that midcapillary pericytes and fibroblasts have no intrinsic smooth muscle differentiation, and that pericytes may be discriminated by expression of $\alpha 1$-integrin and chondroitin sulfate. $(B)$ Fibroblasts $(a-c)$, VSMCs $(d-f)$, and pericytes $(g-i)$ are shown by phase contrast microscopy $(a, d$, and $g)$, and immunoperoxidase staining with $\alpha$-sm actin $(b, e$, and $h)$ or chondroitin sulfate $(c, e, i)$. The peroxidase cytochemistry is counterstained with hematoxylin to outline the cell nuclei. Note that only VSMCs stain with $\alpha$-sm actin while pericytes stain with chondroitin sulfate. $a, d$, and $g, \times 210 ; b-c, e-f$, and $h-i$ 

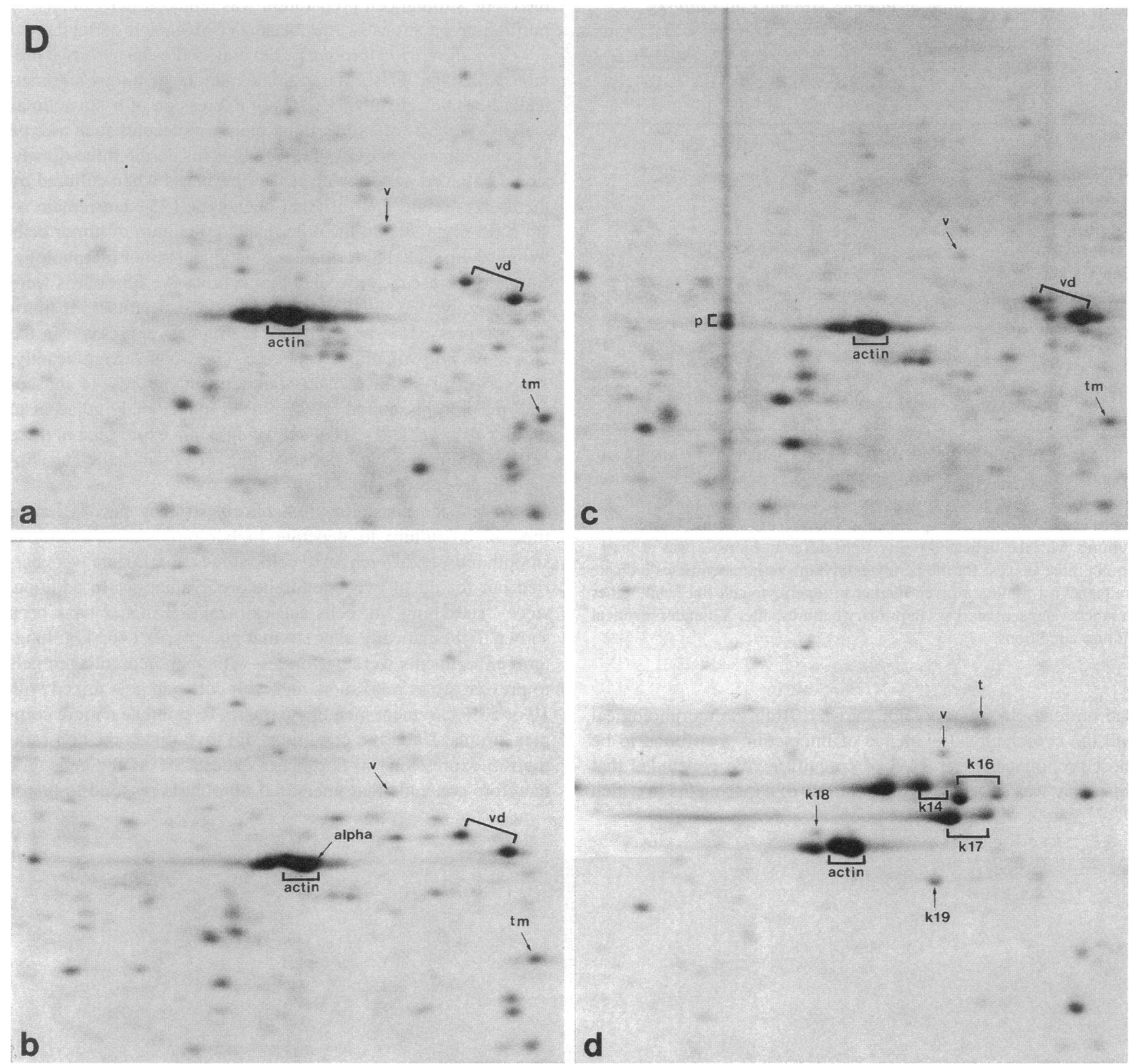

$\times 80$; bar, $50 \mu \mathrm{m}$. (C) IEF followed by immunoblotting against $\alpha$-sm actin revealed that whereas fibroblasts (Fib) and pericytes (Per) expressed $\beta$ - and $\gamma$-nonmuscle actin only, VSMCs (SMC) expressed $\alpha$-sm actin as well. SDS-PAGE and immunoblotting against sm-myosin ( $s m-m y o s i n)$ revealed bands at $M_{\mathrm{r}} 200$ and 204 in VSMCs only. $(D)$ 2-D gel electrophoresis showed distinct protein patterns in fibroblasts $(a)$, VSMCs $(b)$, and pericytes $(c)$ as compared with epithelial cells $(d)$. (alpha, $\alpha$-sm actin; $v$, vimentin; $v d$, vimentin degradation products; $t m$, tropomyosin; $p$, pericyte-associated protein; $t$, tubulin; $k 14,16,17,18,19$, keratin $14,16,17,18$, and 19).

To ascertain further that the separated cells were in fact different from each other beyond the above markers, we compared their two-dimensional gel protein patterns under identical culture conditions. As seen in Fig. $2 \mathrm{D}$, each cell type had its own, individual protein profile distinct from the others. The fibroblast profile resembled that previously published for human dermal fibroblasts (41); the VSMCs and pericytes also had distinct patterns. All differed from glandular epithelial cells. Collectively, these data led us to conclude that our cultures were sufficiently pure for a logical interpretation of the coculture experiments.

Stromal-tumor cell interactions to recapitulate the microen- vironment in situ. When grown inside collagen gels in the absence of stromal cells, tumor cells formed balls with smooth edges (Fig. 3, $a$ and $b$ ). In contrast, when co-cultured with a mix of stromal cells, tumor cells responded by invading the collagen gel and undergoing morphological organization similar to that seen in situ (Fig. 3, $c-f$ ). Indeed, a cross-section of such cultures is difficult to distinguish from a tumor section (compare Fig. 3, $e$ and $f$ ). The interactions in three dimension further resulted in correct modulation of tumor extracellular matrix. The ratio of laminin (normal) to tenascin (tumor) was similar in sections of tumors and the tumor environment assay (compare Fig. 4, $a-c$ with $d-f$ and $g-i$ ). Stromal cells alone 
Table I. Characterization of Purified Stromal Cell Cultures

\begin{tabular}{lccc}
\hline & \multicolumn{3}{c}{ Percentage of immunoreactive cells } \\
\cline { 2 - 4 } & $\begin{array}{c}\text { Fibroblasts } \\
{[\mathrm{n}=23]}\end{array}$ & $\begin{array}{c}\text { VSMC } \\
{[\mathrm{n}=17]}\end{array}$ & $\begin{array}{c}\text { Pericytes } \\
{[\mathrm{n}=23]}\end{array}$ \\
\hline & $n=23^{*}$ & $n=17^{*}$ & $n=23^{*}$ \\
Myogenic markers & & & \\
$\quad \alpha$-sm actin & $<5$ & 77 & $0(<1) \ddagger$ \\
Calponin & $<1$ & 48 & $3(9)$ \\
sm-myosin & $<1$ & 55 & $0(0)$ \\
Cell markers & & & \\
Chondroitin sulfate & $<1$ & 17 & $69(85)$ \\
$\alpha 1$-integrin & 2 & 73 & $96(67)$ \\
Keratin & 0 & $<1$ & $0(0)$ \\
HLA-DQ & 3 & 4 & $0(\mathrm{ND})$ \\
Factor VIII & 0 & 19 & $4(0)$ \\
\hline
\end{tabular}

* The total number of biopsies from which the indicated stromal cell population were purified in the present study. ${ }^{\ddagger}$ Numbers represent means of $3 \times 50$ immunoperoxidase-stained cells counted from the best set of three consecutive experiments. The success rate in obtaining the cultures with the indicated purity from different biopsies was at least one in three (lowest for the pericytes). Numbers in parentheses indicate frequency of finding a given marker in a pericyte cell line while other numbers represent markers in primary cultures, after $3 \mathrm{~d}$ under identical culture conditions.

had no tenascin staining (not shown). Both the morphological and the cytochemical evidence of interaction was found to be most pronounced after $14 \mathrm{~d}$ of co-culture. We concluded that this assay was suitable for the next line of experiments in which the crude stromal cell preparation was replaced individually by purified preparations of fibroblasts, VSMCs, and pericytes.

Co-culture with fibroblasts. Several studies have shown previously that fibroblasts in traditional monolayer culture automatically become activated in terms of expression of $\alpha$-sm actin as well as synthesis of extracellular matrix molecules such as type IV collagen and tenascin $(11,42-44)$. Inside the three-dimensional collagen gels, however, the fibroblasts when cultured by themselves retain their original phenotype (45) and remain $\alpha$ sm actin negative. On the other hand, co-culture of tumor cells with fibroblasts led to formation of a typical tumor morphology. Immunofluorescence revealed that nonreactive fibroblasts were readily converted into myofibroblasts in that almost all fibroblasts expressed $\alpha$-sm actin with the highest expression in the closest vicinity of tumor cell nests (Fig. $5 \mathrm{~A}$ ). Significantly, expression of sm-myosin appeared in only $<5 \%$ of the cocultured fibroblasts and only in those immediately adjacent to tumor cells (Table II). The level of calponin expression in these cells was intermediate between that of $\alpha$-sm actin and smmyosin (Fig. 5 B; Table II).

To test the possibility that fibroblasts may need a longer time in co-culture to generate higher numbers of elaborate smooth muscle differentiated cells, some experiments were carried out for up to two months before evaluation. In addition, since "stretching" of cells and extracellular matrix have been shown to dramatically alter stromal phenotypes $(46,47)$, longterm experiments were performed with anchored collagen gels to prevent stress relaxation, and with collagen gels mixed with 10 or $50 \%$ basement membrane matrix to simulate a more complex stroma. Under no conditions did myo-differentiation (smmyosin expression) in fibroblasts exceed $5 \%$ of the cells. We therefore conclude that interstitial fibroblasts respond to tumor
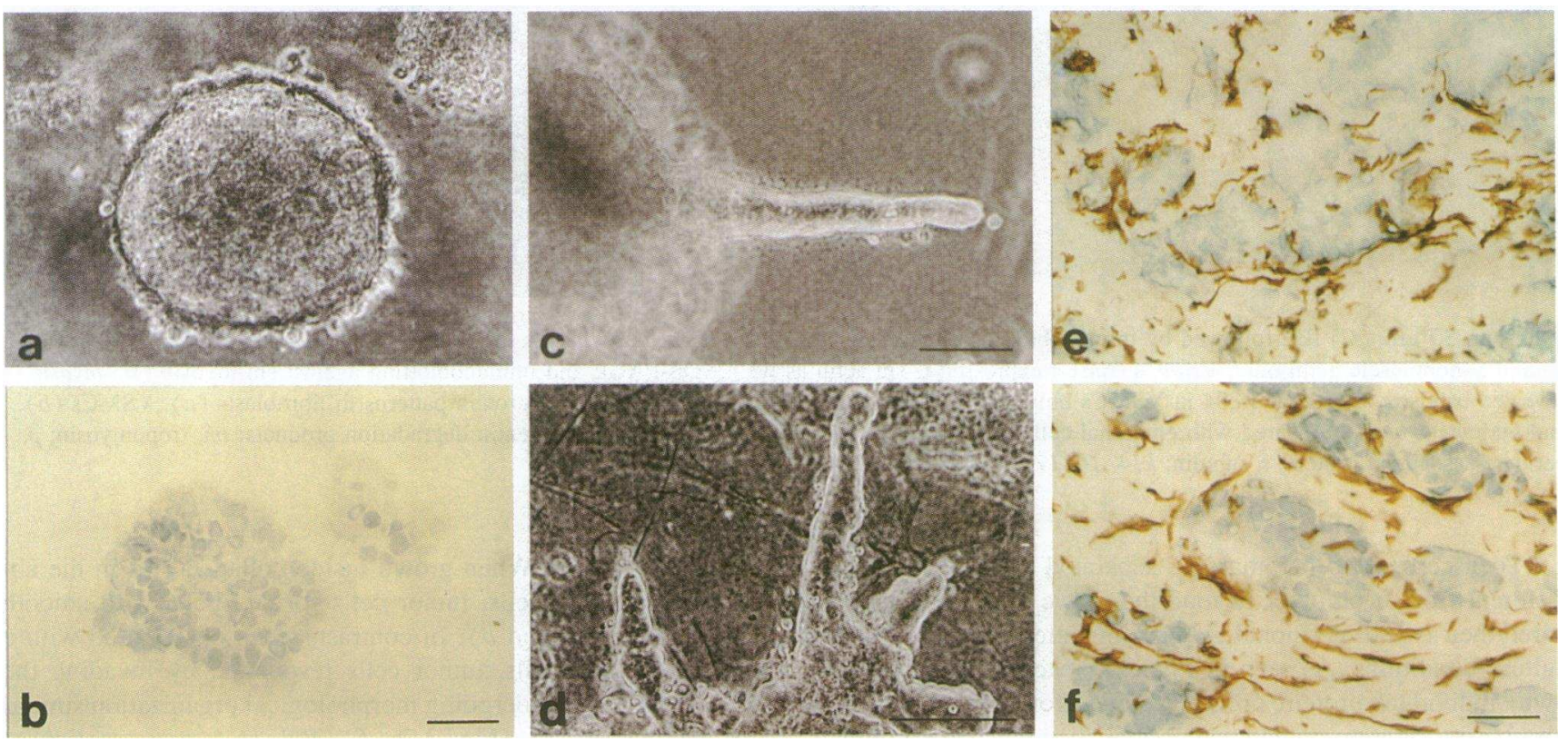

Figure 3. The tumor environment assay: recapitulation of tumor histology when stromal cells are cocultured with tumor cells in three dimension. Tumor cells formed spherical colonies ( $a$ and $b$ ) when cultured alone inside type I collagen gels as demonstrated by phase contrast microscopy $(a)$, and did not express vimentin in immunoperoxidase stained cryosections counter-stained with hematoxylin $(b)$. Co-cultivation with stromal cells in tumor environment assay ( $c$ and $d$ ) resulted in tumor cell spreading along stromal cells $(c)$, and interaction increased with stromal cell density $(d)$. Immunoperoxidase staining for vimentin and counter-staining of nuclei with hematoxylin $(e$ and $f)$ showed that the typical histology of tumors in vivo $(e)$ was virtually reproduced in culture $(f) . a, b, e$, and $f, \times 160$; bar, $50 \mu \mathrm{m} ; c \times 110$; bar, $100 \mu \mathrm{m} ; d \times 280 ;$ bar, $50 \mu \mathrm{m}$. 

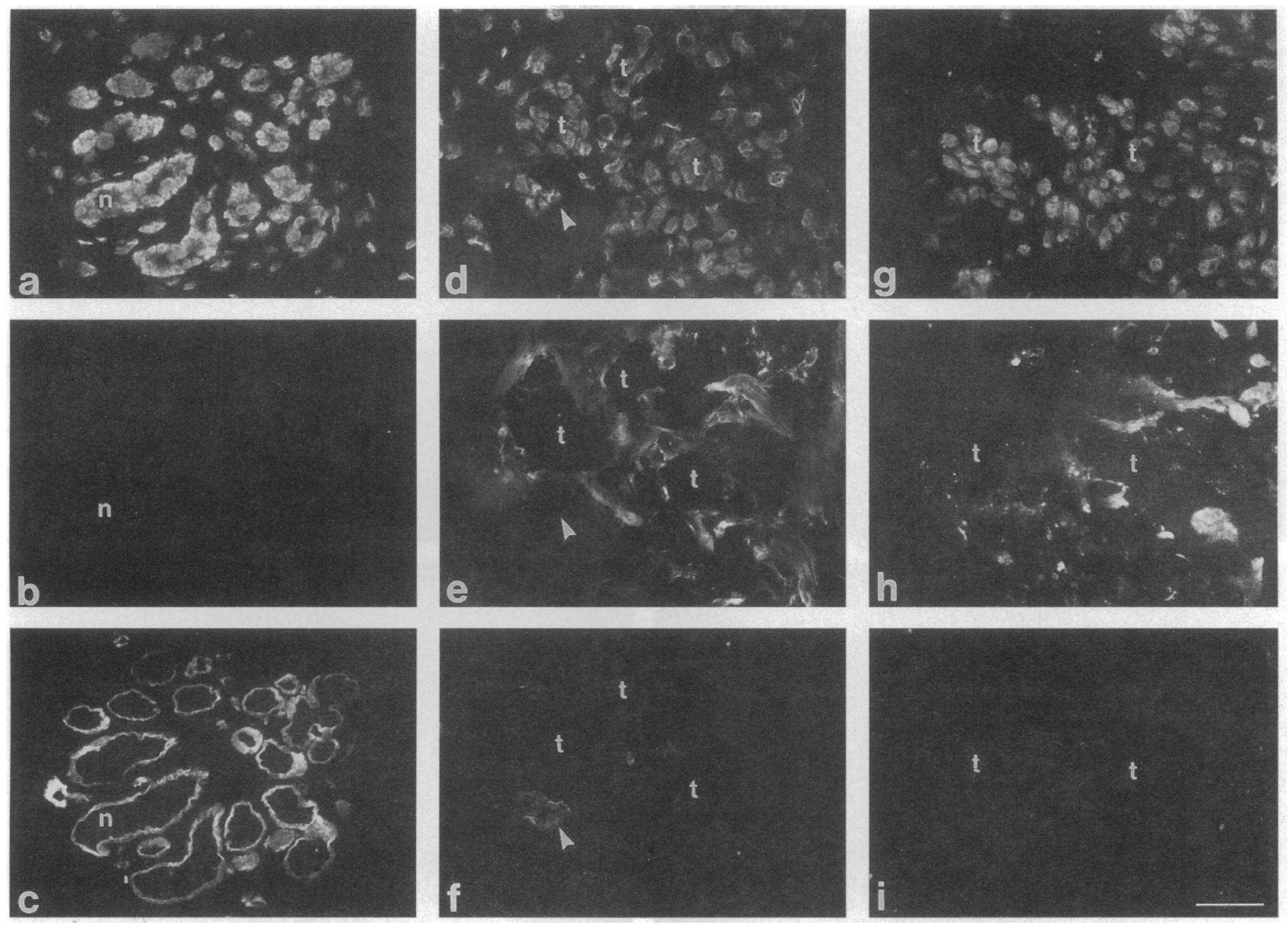

Figure 4. Expression of extracellular matrix components in the tumor environment assay also mimics tumors in situ. Cryosections of normal breast $(a-c)$, a typical tumor in vivo $(d-f)$, and the tumor environment assay $(g$ and $h)$ were counter-stained with Hoechst $(a, d$, and $g)$ to outline morphology, and double stained by immunofluorescence for tenascin $(b, e$, and $h)$ and laminin $(c, f$, and $i)$. Whereas no tenascin was found in normal tissue $(b)$, it was present in the stroma surrounding tumor cell nests $(e$ and $h) ; t$, tumor cells. Laminin was found in basement membrane lining normal breast epithelium $(n)$ and larger blood vessels $(f$; arrowhead), but no immunoreactivity to laminin was observed either in the tumor (except in occasional focal areas of recruited VSMCs; see below; $f, i$ ) or the tumor environment assay. $\times 180$; bar, $50 \mu \mathrm{m}$.

environment primarily by partial conversion toward a myogenic phenotype with the strongest expression closest to tumor cells. Based on these criteria for a fibroblastic origin of myofibroblasts, we set out to test how often a pattern like this occurred in the stroma of tumors in vivo. We found that whereas the above described myogenic response was ubiquitously present in all tumors examined as part of a larger composite pattern (10/10, see below), a uniform and exclusive contribution from fibroblasts occurred in 5/10 (Fig. 5 A; Table II).

Co-culture with VSMCs. Inclusion of purified VSMCs in the assay resulted in a gross tumor morphology essentially resembling that of tumor/fibroblasts co-cultures. However, the complete smooth muscle differentiation program, which is the intrinsic property of these cells, was retained throughout the experimental period in the absence of both vascular organization and endothelial cells, and independently of the presence of tumor cells. Immunofluorescence revealed that the smooth muscle phenotype of VSMCs comprised the coordinate expression of $\alpha$-sm actin, calponin and sm-myosin, irrespective of the cellular position relative to tumor cells (Fig. $6 A, a$ and $b$; Table II). In addition to converted fibroblasts, four out of ten tumors contained a significant proportion of myofibroblasts resembling VSMCs (Fig. $6 A, c$ and $d$ ). These were seen mainly as foci in areas of highly fibrotic tissue (desmoplasia).

For the above to be correct, one has to assume that VSMCs could, in fact, leave blood vessels in response to proximity to tumors. To test this, entire organoids of blood vessels were cocultured with tumor cells. Within one week, some of these blood vessels turned into a thin central core of cells which was left behind after an excessive migration of presumptive VSMCs into the collagen gel (Fig. $6 \mathrm{~B}$ ). Interestingly, some blood vessels stayed completely unaffected under the same conditions and no conversion occurred in control cultures with blood vessels alone (not shown). To identify the affected blood vessels, sections of these gels were triple stained with antibodies to tumor cells, to a venous endothelial cell surface marker, and to sm-myosin (Fig. $6 \mathrm{~B}$ ). It was clearly shown that the cells recruited into the tumor environment were indeed derived from VSMCs based on the strong expression of sm-myosin, and that these came predominantly from the venous portion of the vessel. This is a surprising finding. To find further evidence that blood vessels can give rise to displaced VSMCs also in vivo, we 

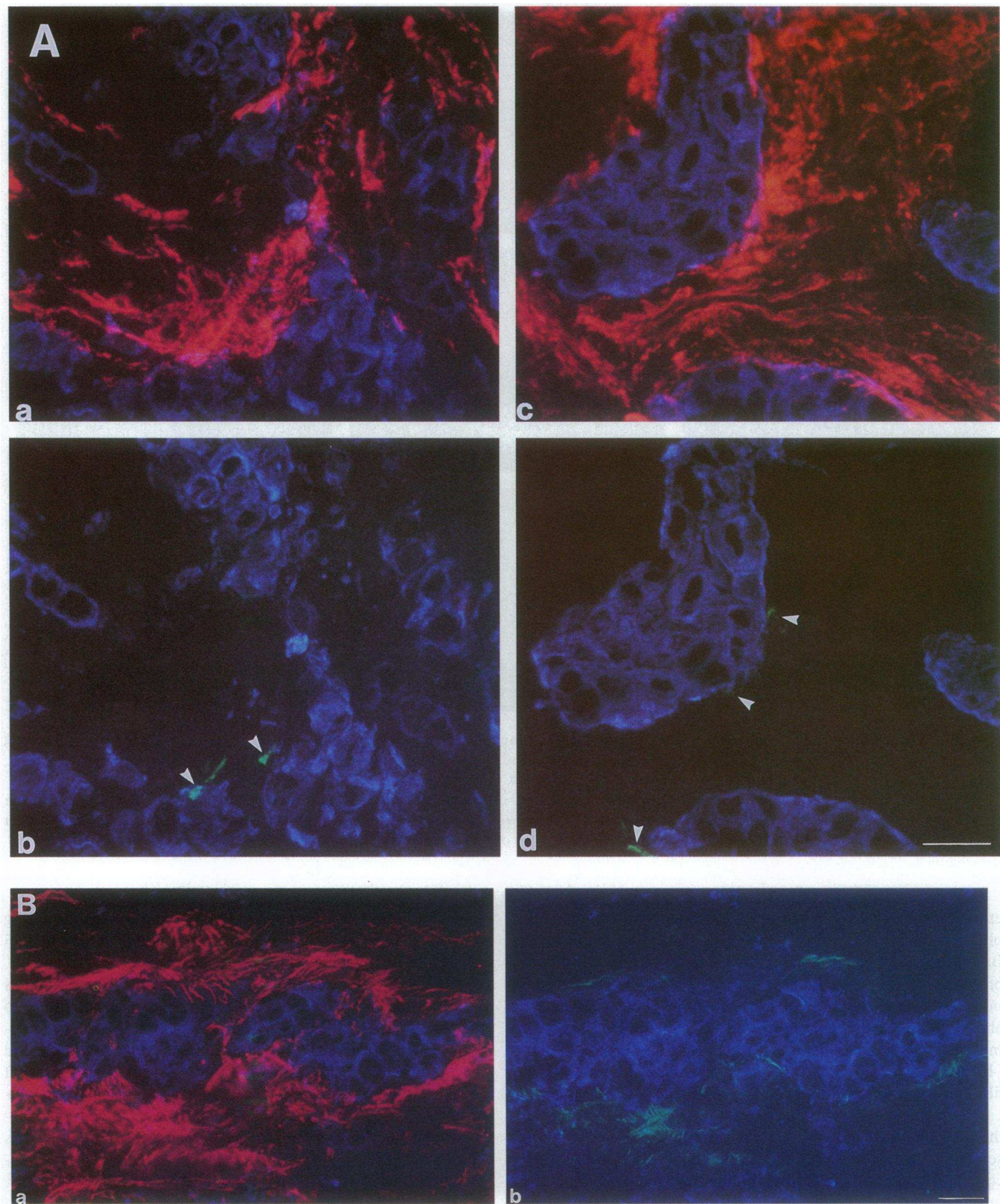

Figure 5. Tumor cells convert negative fibroblasts to reactive fibroblasts in collagen gels. $(A)$ Cryosections were triple-stained for $\alpha$-sm actin $(a$, $c ; r e d), \mathrm{sm}$-myosin ( $b, d ;$ green $)$ and cytokeratin (blue). Most fibroblasts converted into $\alpha$-sm actin-positive myofibroblasts in the tumor environment assay $(a)$ and a few, in addition, acquired sm-myosin ( $b$; arrowheads). The experimentally generated "tumor" has a striking similarity to tumors in vivo $(c, d)$. Note that myofibroblasts in both the assay and the tumor accumulate around tumor cells. $(B)$ Cryosections were triple stained for $\alpha$-sm actin $(a ; r e d)$, calponin $(b ;$ green $)$ and cytokeratin (blue). Only fibroblasts closest to tumor cells were induced to express calponin. $\times 470$; bar, $25 \mu \mathrm{m}$. 
Table II. Expression of Myogenic Markers in Stromal Cells in the Tumor Environment Assay and Primary Tumors

\begin{tabular}{|c|c|c|c|}
\hline & \multicolumn{3}{|c|}{ Stromal cell staining } \\
\hline & Fibroblasts & VSMC & Pericytes \\
\hline & $n=12^{*}$ & $n=8^{*}$ & $n=4^{*}$ \\
\hline \multicolumn{4}{|l|}{ Myogenic markers } \\
\hline$\alpha$-sm actin & +++ & +++ & $+1-$ \\
\hline calponin & ++ & +++ & - \\
\hline sm-myosin & + & ++ & - \\
\hline $\begin{array}{l}\text { No of tumors with similar } \\
\text { myogenic stromal profile }\end{array}$ & $10 / 10^{\ddagger}$ & $4 / 10$ & $1 / 10$ \\
\hline
\end{tabular}

* Total number of experiments with the indicated stromal cell type. $(+++)$ strong staining in more than $75 \%$ the cells; $(++)$ staining in about $25-50 \%$ of the cells; $(+)$ staining in less than $5 \%$ of the cells; $(+/-)$ occasional staining in some experiments; $(-)$ no staining.

${ }^{\ddagger}$ Five of these tumors showed exclusive contribution from converted fibroblasts.

analyzed the cytoarchitecture of blood vessels in tissue with and without high numbers of interstitial sm-myosin differentiated stromal cells. As seen in Fig. $6 \mathrm{~B}$, the absence of highly myodifferentiated interstitial cells coincided with intact blood vessels; in contrast, blood vessels were essentially denuded of mural cells whenever present in areas of strong interstitial myo-differentiation, suggesting a displacement of VSMCs from the wall of the blood vessel to the interstitial stroma. The myo-differentiated stromal cells of presumptive blood vessel origin differed from those of fibroblastic origin not only by their position and by the frequent, coordinated and strong expression of $\alpha$-sm actin, sm-myosin, calponin, but also by the deposition of a laminin-containing basement membrane (Fig. $6 \mathrm{~B}$ ).

To exclude the possibility that the vascular smooth musclelike myofibroblasts could originate from myoepithelial cells, another highly myodifferentiated cell type, these cells were isolated as previously described (26), and were confronted with the tumor cells. A radical difference between myofibroblasts and myoepithelial cells emerged in this experiment, since the latter failed to down regulate a critical keratin-associated antigen $(52 \mathrm{~K})$, otherwise incompatible with the very definition of myofibroblasts (not shown).

Co-culture with pericytes. Tumor cells co-cultured with pericytes became motile, indicating that this particular part of tumor cell-stroma cell interaction may depend on factors shared by all three stromal cell types. However, midcapillary pericytes clearly differed from both fibroblast and VSMCs by having none, or only a very low level, of $\alpha$-sm actin and calponin, and no smmyosin induced by tumor environment. These cells, however, had a distinct expression of $\alpha 1$-integrin (Fig. 7; Table II). Of ten tumors examined in detail, only one contained areas of stroma typical of pericyte conversion. We therefore conclude that while pericytes can contribute to the tumor stroma, their conversion to a myofibroblast phenotype is quite limited. Collectively, we are therefore left with the venous VSMCs as the major candidate in the source of focal accumulations of myofibroblasts with high levels of coordinated myogenic differentiation.

\section{Discussion}

Studies of breast cancer induction, progression and metastasis have almost exclusively focused on the cancer cell (epithelia) itself. It is well known, however, that the stroma is also altered rapidly and extensively. We now know that the microenvironment of breast epithelial cells profoundly influences both the morphology and the differentiated function of the mammary gland $(48,49)$. It is thus logical to suspect that the nature of the altered microenvironment would also influence the behavior of the tumor cells and may influence the course of progression. To understand the molecular basis of this interaction, however, would require a definition of the microenvironment itself and thus, a physiologically relevant culture model for breast cancer.

We have shown previously that normal and malignant breast epithelial cells can be rapidly distinguished from each other in a three-dimensional basement membrane assay (50). To create a replica of a tumor, however, would require creating an assay where the tumor environment is reproduced as closely as possible. The latter is not possible without understanding the functional characteristics and the origin of cells in the stromal reaction. The present study, therefore, accomplishes three tasks: it provides new methods and markers for isolation and characterization of the prominent stromal cells from human breast; it provides an in depth analysis of the origin of "myofibroblasts," an early and pronounced component of the stromal reaction; and finally, it provides a versatile assay for recreating the tumor environment in culture.

The molecules reported to participate in the reactive phenotype (also described for inflammation and wound healing) are the cytoskeletal proteins desmin $(17,51), \alpha$-sm actin $(1,2)$, sm-myosin (16), the actin-associated proteins calponin and caldesmon (16), the extracellular matrix receptor $\alpha 1$-integrin $(16,52)$, and the basement membrane molecules type IV collagen and laminin. It has been speculated that resident fibroblasts $(8,11-14)$, VSMCs $(1,2,5,18)$ or capillary pericytes $(18)$ are the source of myofibroblasts. Theoretically, myoepithelial cells could also take part. We set out to provide an experimental model to test which of these hypotheses may be true. Our results indicate that myoepithelial cells are not involved, pericytes may play a small role in the tumor stroma, and the VSMCs and the fibroblasts are the primary players.

A number of potentially important findings emerges from our results. Purified, resident normal fibroblasts, once in the tumor environment assay, readily convert into $\alpha$-sm actin-expressing myofibroblasts in a manner similar to that of true reactive tissue. Having established markers in addition to $\alpha$-sm actin, we were able to show that the myogenic differentiation in the majority of cells is partial, both in vivo and in the culture assay: sm-myosin and calponin are only induced in a fraction of cells closest to tumor cells. We conclude that resident fibroblasts in the stroma are the cellular source of those myofibroblasts which show this pattern of conversion in vivo. Our results that the cells closest to tumor cells show the strongest conversion can be explained by a concentration gradient of growth factors originating from the tumor cells. Transforming growth factor- $\beta$ (TGF- $\beta$ ) has been identified as the activity responsible for induction of $\alpha$-sm actin in cultured fibroblasts and is produced by tumor cells $(14,15$, 53 ). We suggest that this activity may originate either from the tumor cells but be carried across the stroma by a cascade of secretion from the converted myofibroblasts. An alternative explanation would be that TGF- $\beta$ already exists in the stroma but needs activation by proteases, and these would be elaborated by tumor cells and the converted fibroblasts. TGF- $\beta$ is synthesized in a latent form and is often immobilized in the extracellular matrix $(54,55)$. In either case, however, this growth factor would 

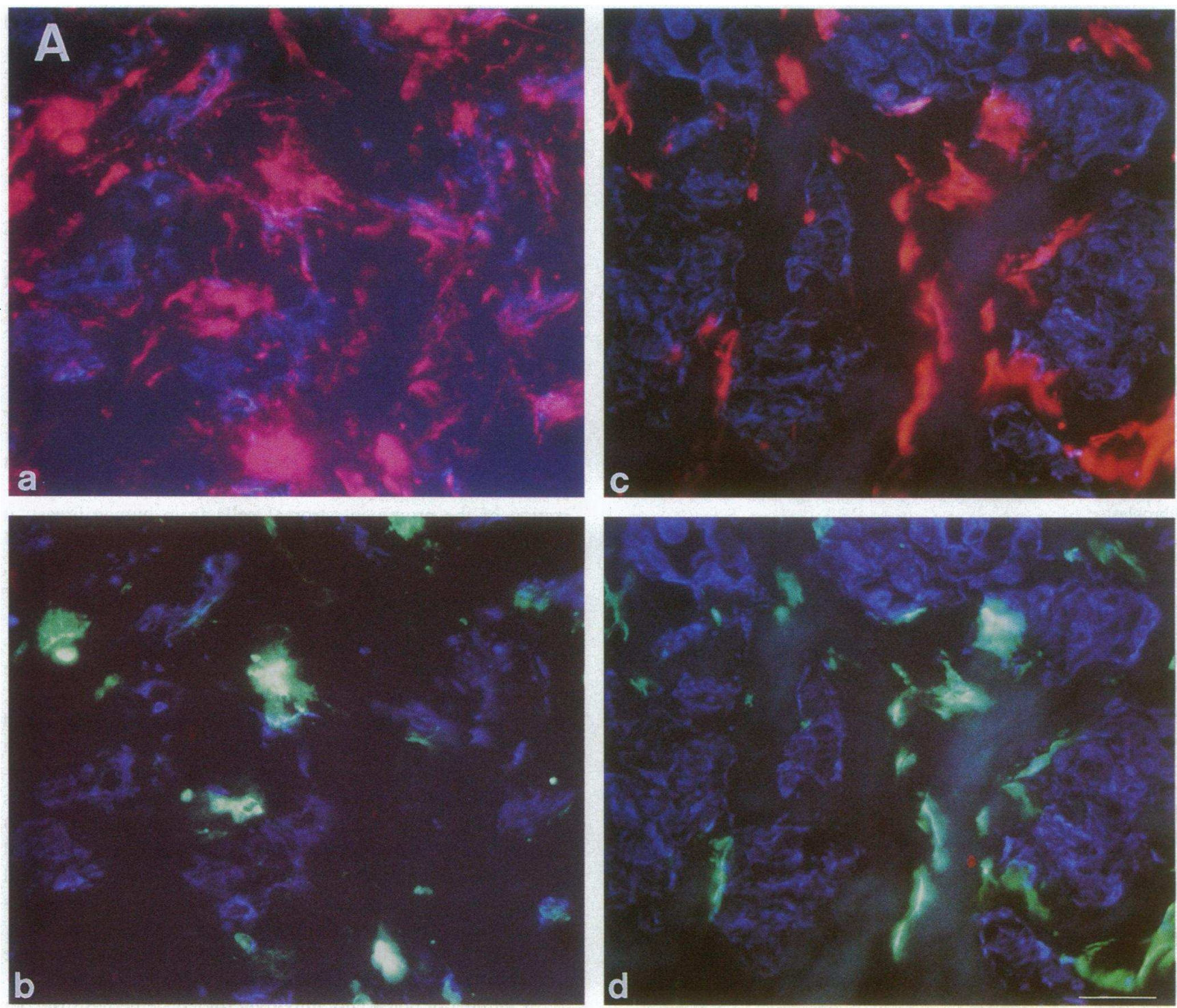

Figure 6. Recreation of a tumor environment with VSMC phenotype. $(A)$ VSMC retain their differentiated function in the tumor environment assay. Cryosections were triple-stained for $\alpha$-sm actin $(a, c ; r e d), \mathrm{sm}$-myosin $(b, d ; g r e e n)$ and cytokeratin (blue). VSMCs retained a strong expression of $\alpha$-sm actin $(a)$ and sm-myosin $(b)$ upon co-culture with tumor cells. One of the tumors with a highly smooth muscle differentiated stroma is shown for comparison $(c, d)$. Clearly both VSMCs and converted fibroblasts localize in between the tumor cell nests. $\times 470$; bar, $25 \mu \mathrm{m}$. $(B)$ Tumor cells can specifically denude the venules in the tumor environment assay. ( $a$ ) Phase contrast microscopy of blood vessels $(b v)$ in collagen gels demonstrated that vascular cells (arrowheads) of vessels were readily attracted by tumor cells $(t)$, however the reaction was not uniform. ( $b$ and $c$ ) To address the reason for heterogeneity, cryosections were triple-stained by immunofluorescence for an endothelial cell marker specific for venules (red), sm-myosin (green) and cytokeratins (blue). It was revealed that the blood vessels (bv) stripped for sm-myosin-positive VSMCs (arrowheads) were only those from the venous portion, and that the VSMCs were attracted into close vicinity of tumor cells $(t)$. $(d$ and $e$ ) In comparison, triple-staining of cryosections of tumors demonstrated that in tumors with no or few sm-myosin-differentiated myofibroblasts, blood vessels were intact $(d)$, whereas in tumors with distinct sm-myosin-differentiated myofibroblasts, blood vessels within the same area were always stripped of VSMCs $(e) .(f)$ The vascular origin of these myofibroblasts in tumors was further confirmed by triple-staining for sm-myosin (green), laminin (red) and cytokeratin (blue). Sm-myosin-positive myofibroblasts derived from blood vessels $(b v)$ showed positive staining for laminin (arrowhead+), whereas those derived from fibroblasts did not (arrowhead-). (a) $\times 160 ;$ bar, $50 \mu \mathrm{m} ;(b$ and $c) \times 470 ; d \times 400 ; e \times 640$; $f \times 780$; bar, $25 \mu \mathrm{m}$.

not be sufficient to induce the more elaborate myogenic phenotype. The induction of the additional markers around the tumor cell nests would require other factors that either get trapped by the ECM upon secretion (e.g., bFGF would attach to heparan sulphate proteoglycan) and/or are dependent on proteolytic activation in the vicinity of the tumors. Other investigators have previously postulated a growth factor gradient to explain the localization of tenascin and stromelysin-3 in stroma of breast carcinoma $(42,56)$. Proteolytic activation has been shown for a number of cell types to rely on a direct interaction between neighboring cells: one producing the relevant enzyme, another binding it to cell surface receptors prior to activation (57-59). In the absence of such heterologous cell-cell interactions, such as the stroma which is not adjacent to the tumor, the physiological 

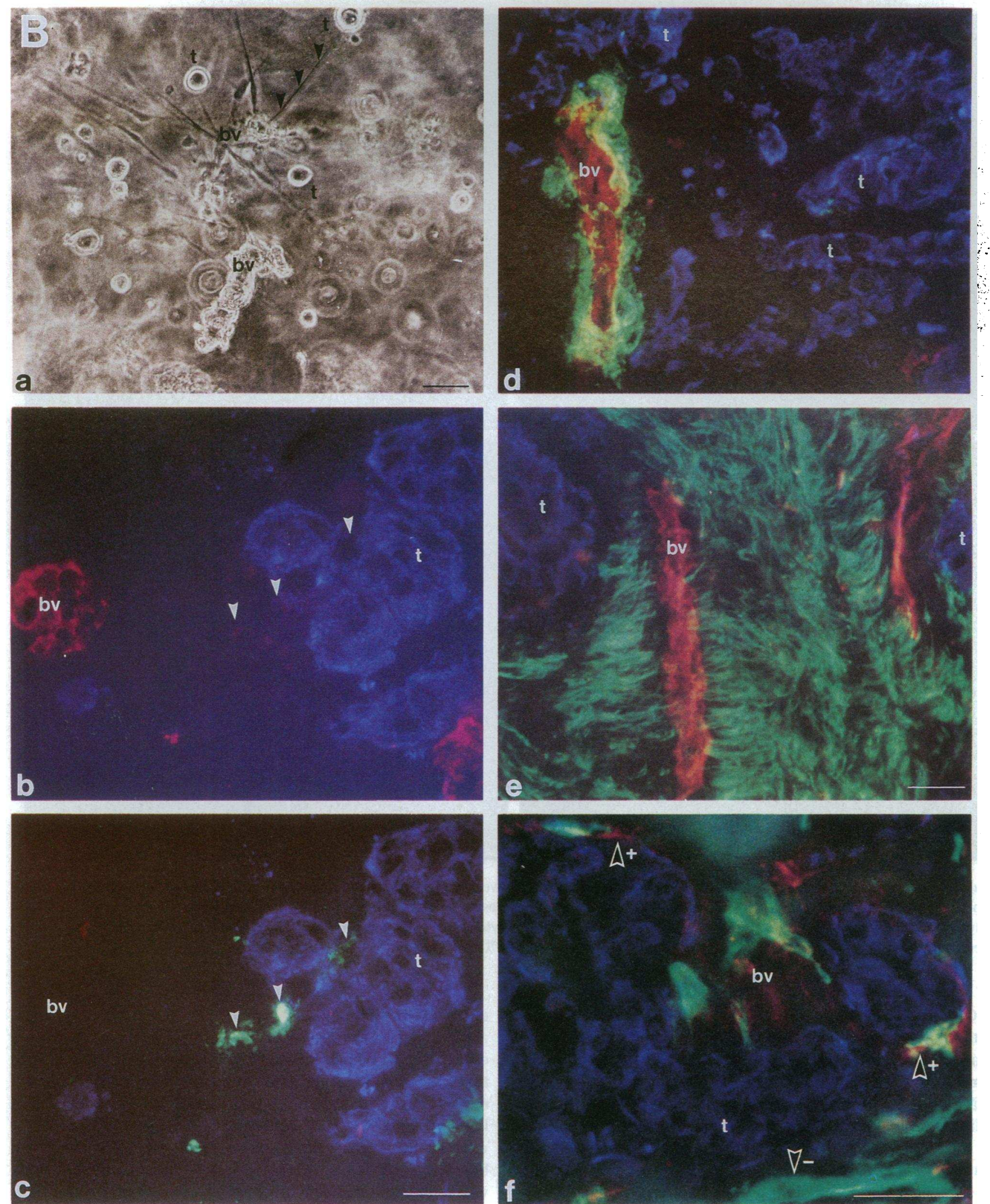

response may fail to appear even in the presence of high levels of the latent activity. Our finding here that purified fibroblasts have a restricted ability for myogenic differentiation in that only $\sim 5 \%$ (and only those in the vicinity of the tumor) can express sm-myosin, is consistent with, and may shed light on, previous

studies on granulation tissue and tumors and presumptive fibroblast cell lines. The coordinate expression of $\alpha$-sm actin and smmyosin in stromal cells has either been reported as not to occur (60), or to appear in $\sim 10-15 \%$ of the entire cell populations $(15,44)$. 

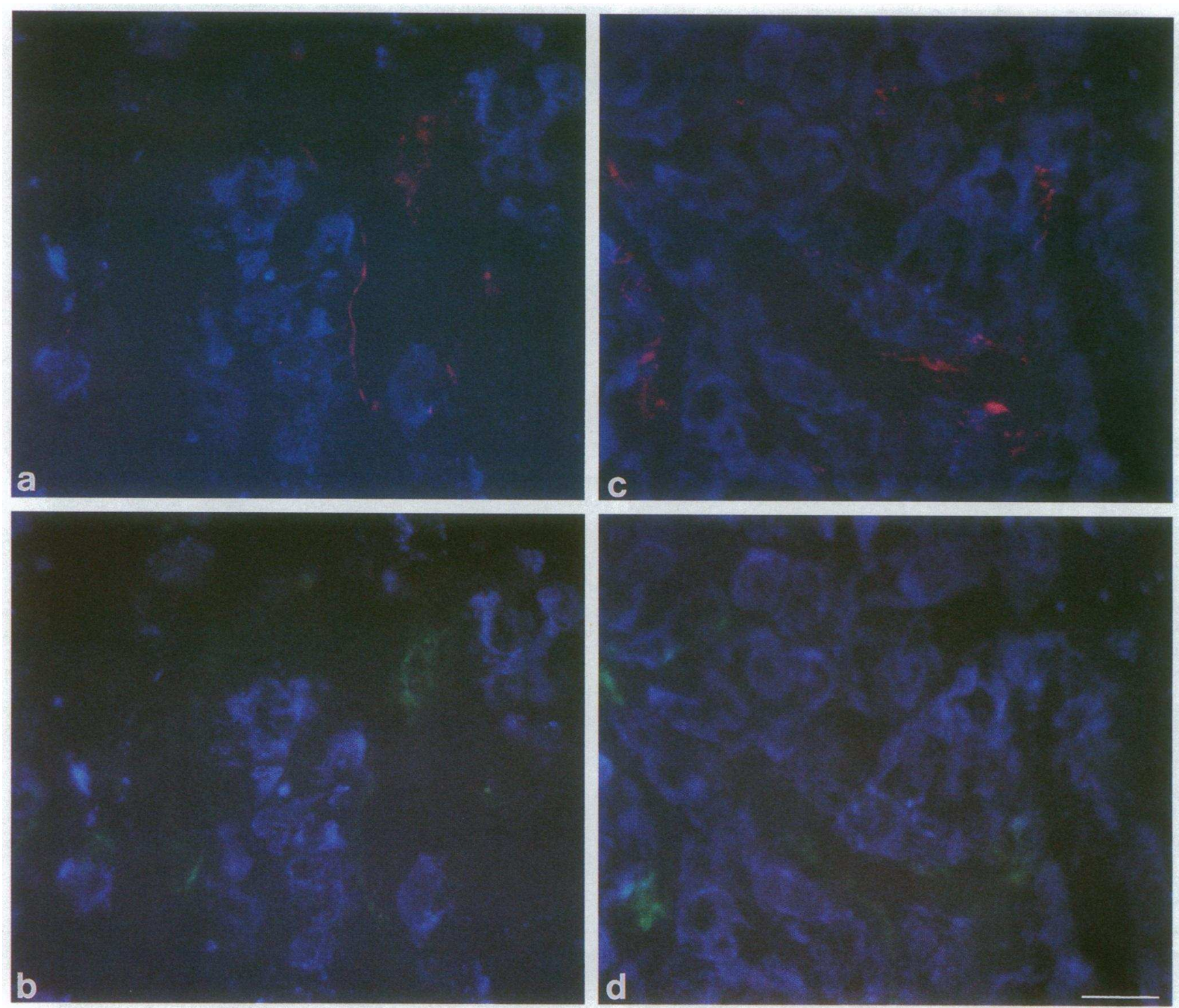

Figure 7. Tumor cells in tumor environment assay convert pericytes to a weakly myogenic phenotype. Cryosections were triple-stained for $\alpha$-sm actin $(a, c ; r e d), \alpha 1$-integrin $(b, d ;$ green) and cytokeratin (blue). Pericytes were induced to express few, weakly stained $\alpha$-sm actin filaments in the tumor environment assay $(a)$, but maintained their characteristic pericyte antigen ( $\alpha 1$-integrin) expression $(b)$. The stroma of one tumor out of ten contained areas that resemble this phenotype in vivo $(c$ and $d) . \times 470 ;$ bar, $25 \mu \mathrm{m}$.

Our previous studies with purified fibroblasts have demonstrated that ectopic expression of $\alpha$-sm actin is the clear result of induction at the level of mRNA in the absence of cell proliferation (14). A similar protocol for purification and cultivation of fibroblasts used in the present study allowed us to rule out proliferation-related changes, and to examine potential events that might otherwise have been obscured by overgrowth of contaminating cells.

Another major observation in the tumor environment assay is that VSMCs on the venous portion of the vessels are mobilized by the tumor cells to move towards the tumor, leaving behind denuded endothelial tubes both in the assay and in situ. Furthermore, these cells do not alter their phenotype when deprived of the endothelial tube. These findings are consistent with a contribution of VSMCs to myofibroblasts in those reactive lesions with foci of cells containing high numbers of smmyosin-expressing cells. The contribution of VSMCs to the concerted myofibroblasts scenario may explain previous puzzling results on sections of reactive tissue: that bleomycin injury of the rat lung, which leads to fibrosis and myofibroblast generation, concurrently results in disruption of blood vessels (5), that reactive stromal cells occasionally deposit basement membrane laminin, type III and V collagen, and elastin $(51,61,62)-$ extracellular matrix components otherwise associated with blood vessel SMCs - and that the intermediate filament desmin, which under normal conditions is only expressed in mural cells of arteries, veins, arterioles and venules, occasionally appear at high frequencies in reactive interstitial stroma $(17,51)$. That these interstitial stromal phenotypic traits in fact are derived from VSMCs is supported by our observations that sm-myosin and basement membrane laminin, when present, are not random, and are consistently co-expressed in the same focal area of cells within the tissues. That VSMCs are exclusively recruited from the venous portion of the vessel is supported by studies of 
expression of caldesmon in sections of reactive stromal tissue. Caldesmon is seen primarily on the arterial portion of the blood vessels (unpublished observations) and never outside the wall of the vessel in reactive lesions (16). Moreover, it is well established that newly formed vessels in tissue remodeling arise from smaller veins and venules only $(20,21)$ and that mural cells are carried along at an early stage (22). It is quite possible, therefore, that these cells, under the prevailing paracrine conditions, and during excessive collagen deposition such as that of desmoplasia, are displaced into the interstitial stroma. In the absence of desmoplasia, angiogenesis proceeds without spillage of mural cells.

We and others have argued in the past that the differentiated state of normal cells is unstable (i.e., not constitutive), and requires continuous regulatory input $(63,64)$. It can therefore be argued that there is still an alternative explanation for the interstitial focal accumulation of stromal cells with a highly coordinated myogenic phenotype: resident fibroblasts may exhibit a much more remarkable plasticity than revealed in the present tumor environment assay. Thus, a coordinated, uniform, ectopic expression of muscle genes could be turned on by master regulatory genes such as that of MyoD1 $(65,66)$. In the case of fibroblasts, this may still be so for the $5 \%$ of cells which are closest to the tumor. In this case, however, a local factor generated by tumor cells themselves would have to activate the master switch. Nevertheless, while this possibility cannot be absolutely ruled out for the focal areas, it is important to note that we have correlated the presence of these areas of highly differentiated myofibroblasts with the appearance of denuded vessels nearby.

Having defined the relative importance of intrinsic cellular programming and environmental regulation for the myogenic differentiation of fibroblasts and VSMCs, we widened our inquiry to include the possible conversion of pericytes. Our present and previous results show clearly that the midcapillary pericytes under normal conditions in vivo do not express $\alpha$-sm actin or sm-myosin (Rønnov-Jessen, L., L. Bissell, and O. W. Petersen, manuscript in preparation). Similar observations have been made with midcapillary pericytes from other microvasculatory beds $(37,39)$. Nehls et al. (37) had argued that a culture technique to obtain $\alpha$-sm actin-negative pericytes was badly needed. In the present study, we used two additional markers for pericytes that we identified with our whole mount assay in situ: chondroitin sulfate and $\alpha 1$-integrin. We were thus able to purify and identify midcapillary pericytes in culture. We find that pericytes deprived of the capillary bed in vivo and in the assay have low levels of $\alpha$-sm actin but refrain from an elaborate smooth muscle differentiation and retain $\alpha 1$-integrin expression, an element of their original phenotype. The observed relative infrequent presence of pericytes outside the capillary bed under reactive conditions is in good agreement with previous findings on tissue sections of tumors $(22,40)$.

Tumor fibroblasts have been reported to exhibit both inhibitory and stimulatory effects on the course of tumor growth and invasion (67-70). It has been shown that wounding-mediated TGF- $\beta$ is a cocarcinogen in tumors induced in chickens, and that anti-TGF- $\beta$ antibodies inhibit breast cancer cell tumorigenicity in nude mice $(71,72)$ (for review see reference 73 ). Conversely, it has been suggested that a highly fibrotic, desmoplastic peritumoral stroma may have an overall negative effect on growth and invasion (74). The diversity of stromal response both among tumors and within a tumor is indicative of dynamic cross talk and signaling among various cell types, growth factors and extracellular matrix. Therefore, the mechanism by which tumors generate the diversity and the consequences of such heterogeneity for progression and therapy must be evaluated carefully.

\section{Acknowledgments}

The authors thank Tove Marianne Lund and Torill Rignes for expert technical assistance, Keld Ottosen for printing the micrographs, and Yvonne Shu for expert secretarial assistance. The Aasted Clinic, the Erichsen Clinic, the Private Clinic, the Søllerød Plastic Surgery Clinic, Bispebjerg Hospital and Hvidovre Hospital are gratefully acknowledged for providing the biopsy material. We also thank Dr. Per Briand, Department of Tumor Endocrinology, Danish Cancer Society, Copenhagen, and Drs. Mary-Helen Barcellos-Hoff and Anthony Howlett, Lawrence Berkeley Laboratory, CA, for critical reading of the manuscript.

This work was supported by the Danish Cancer Society, the Danish Medical Research Council, the Gangsted Foundation, the Haensch Foundation, the Novo Foundation, the Thaysen Foundation, the WedellWedellsborg Foundation, and the Willumsen Foundation grants to O. W. Petersen and L. Rønnov-Jessen and in part by the Health Effects Research Division, Office of Health and Environmental Research, U.S. Department of Energy under Contract DE-AC03-76-SF00098 and a Guggenheim Fellowship to M. J. Bissell held at École Normale Superieure, Paris.

\section{References}

1. Skalli, O., P. Ropraz, A. Trzeciak, G. Benzonana, D. Gillessen, and G Gabbiani. 1986. A monoclonal antibody against $\alpha$-smooth muscle actin: a new probe for smooth muscle differentiation. J. Cell Biol. 103:2787-2796.

2. Tsukada, T., M. A. McNutt, R. Ross, and A. M. Gown. 1987. HHF35, a muscle actin-specific monoclonal antibody II. Reactivity in normal, reactive and neoplastic human tissues. Am. J. Pathol. 127:389-402.

3. Sappino, A.-P., O. Skalli, B. Jackson, W. Schürch, and G. Gabbiani. 1988 Smooth-muscle differentiation in stromal cells of malignant and non-malignant breast tissues. Int. J. Cancer. 41:707-712.

4. Eddy, R. J., J. A. Petro, and J. J. Tomasek. 1988. Evidence for the nonmuscle nature of the "myofibroblast" of granulation tissue and hypertropic scar. An immunofluorescence study. Am. J. Pathol. 130:252-260.

5. Mitchell, J., J. Woodcock-Mitchell, S. Reynolds, R. Low, K. Leslie, K. Adler, G. Gabbiani, and O. Skalli. 1989. $\alpha$-Smooth muscle actin in parenchymal cells of bleomycin-injured rat lung. Lab. Invest. 5:643-650.

6. Sappino, A.-P., P.-Y. Dietrich, O. Skalli, S. Widgren, and G. Gabbiani 1989. Colonic pericryptal fibroblasts. Differentiation pattern in embryogenesis and phenotypic modulation in epithelial proliferative lesions. Virchows Arch. A Pathol. Anat. Histopathol. 415:551-557.

7. Czernobilsky, B., E. Shezen, B. Lifschitz-Mercer, M. Fogel, A. Luzon, N. Jacob, O. Skalli and G. Gabbiani. 1989. Alpha smooth muscle actin ( $\alpha$-SM actin) in normal human ovaries, in ovarian stromal hyperplasia and in ovarian neoplasms. Virchows. Arch. B Cell Pathol. 57:55-61.

8. Darby, I., O. Skalli, and G. Gabbiani. 1990. $\alpha$-Smooth muscle actin is transiently expressed by myofibroblasts during experimental wound healing. $L a b$. Invest. 63:21.

9. Brouty-Boyé, D., H. Raux, B. Azzarone, A. Tamboise, E. Tamboise, S. Béranger, V. Magnien, I. Pihan, L. Zardi, and L. Israël. 1991. Fetal myofibroblastlike cells isolated from post-radiation fibrosis in human breast cancer. Int. J. Cancer. 47:697-702.

10. Cintorino, M., E. Bellizzi de Marco, P. Leoncini, S. A. Tripodi, F. C. Ramaekers, A.-P. Sappino, A. Schmitt-Gräff, and G. Gabbiani. 1991. Expression of $\alpha$-smooth muscle actin in stromal cells of the uterine cervix during epithelial neoplastic changes. Int. J. Cancer 47:843-846.

11. Rønnov-Jessen, L., B. van Deurs, J. E. Celis, and O. W. Petersen. 1990 Smooth muscle differentiation in cultured human breast gland stromal cells. $L a b$. Invest. 63:532-543.

12. Rønnov-Jessen, L., J. E. Celis, B. van Deurs, and O. W. Petersen. 1992 A fibroblast-associated antigen: characterization in fibroblasts and immunoreactivity in smooth muscle differentiated stromal cells. J. Histochem. Cytochem. 40:475-486.

13. Rønnov-Jessen, L., B. van Deurs, M. Nielsen, and O. W. Petersen. 1992. Identification, paracrine generation and possible function of human breast carcinoma myofibroblasts in culture. In Vitro Cell. \& Dev. Biol. 28A:273-283.

14. Rønnov-Jessen, L., and O. W. Petersen. 1993. Induction of $\alpha$-smooth muscle actin by transforming growth factor- $\beta 1$ in quiescent human breast gland 
fibroblasts. Implications for myofibroblast generation in breast neoplasia. Lab. Invest. 68:696-707.

15. Desmoulière, A., A. Geinoz, F. Gabbiani, and G. Gabbiani. 1993. Transforming growth factor- $\beta 1$ induces $\alpha$-smooth muscle actin expression in granulation tissue myofibroblasts and in quiescent and growing cultured fibroblasts. $J$. Cell Biol. 122:103-111.

16. Lazard, D., X. Sastre, M. G. Frid, M. A. Glukhova, J.-P. Thiery, and V. E. Koteliansky. 1993. Expression of smooth muscle-specific proteins in myoepithelium and stromal myofibroblasts of normal and malignant human breast tissue. Proc. Natl. Acad. Sci. USA. 90:999-1003.

17. Skalli, O., W. Schürch, T. Seemayer, R. Lagacé, D. Montandon, B. Pittet, and G. Gabbiani. 1989. Myofibroblasts from diverse pathologic settings are heterogeneous in their content of actin isoforms and intermediate filament proteins. Lab. Invest. 60:275-285.

18. Skalli, O., M.-F. Pelte, M.-C. Peclet, G. Gabbiani, P. Gugliotta, G. Bussolati, M. Ravazzola, and L. Orci. 1989. $\alpha$-Smooth muscle actin, a differentiation marker of smooth muscle cells, is present in microfilamentous bundles of pericytes. J. Histochem. Cytochem. 37:315-321.

19. Rockey, D. C., and S. L. Friedman. 1992. Cytoskeleton of liver perisinusoidal cells (lipocytes) in normal and pathological conditions. Cell Motil. Cytoskeleton. 22:227-234.

20. Folkman, J. 1985. Tumor angiogenesis. Adv. Cancer Res. 43:175-203.

21. Folkman, J. 1986. How is blood vessel growth regulated in normal and neoplastic tissue? - G. H. A. Clowes memorial award lecture. Cancer Res. 46:467473.

22. Schlingemann, R. O., F. J. R. Reitveld, F. Kwaspen, P. C. M. van de Kerkhof, R. M. W. de Waal, and D. J. Ruiter. 1991. Differential expression of markers for endothelial cells, pericytes, and basal lamina in the microvasculature of tumors and granulation tissue. Am J. Pathol. 138:1335-1347.

23. Chamley-Campbell, J., G. R. Campbell, and R. Ross. 1979. The smooth muscle cell in culture. Physiol. Rev. 59:1-61.

24. Betz, E., P. Fallier-Becker, K. Wolburg-Buchholz, and Z. Fotev. 1991. Proliferation of smooth muscle cells in the inner and outer layers of the tunica media of arteries: an in vitro study. J. Cell. Physiol. 147:385-395.

25. Petersen, O. W., and B. van Deurs. 1988. Growth factor control of myoepithelial-cell differentiation in cultures of human mammary gland. Differentiation. 39:197-215.

26. Petersen, O. W., S. H. Hansen, I. Laursen, and B. van Deurs. 1989. Effect of insulin on growth and expression of smooth muscle isoactin in human breast gland myoepithelial cells in a chemically defined culture system. Eur. J. Cell Biol. 50:500-509.

27. Frid, M. G., B. V. Shekhonin, V. E. Kotelianski, and M. A. Glukhova. 1992. Phenotypic changes of human smooth muscle cells during development: late expression of heavy caldesmon and calponin. Dev. Biol. 153:185-193.

28. Pallesen, G., S. Nielsen, and J. E. Celis. 1987. Characterization of a monoclonal antibody (BG3C8) that reacts with basal cells of stratified epithelia. Histopathology. 11:591-601.

29. Schlingemann, R. O., G. M. Dingjan, J. J. Emeis, J. Blok, S. O. Warnaar, and D. J. Ruiter. 1985. Monoclonal antibody PAL-E specific for endothelium. Lab. Invest. 52:71-76.

30. Laemmli, U. K. 1970. Cleavage of structure protein during assembly of the head of the bacteriophage T4. Nature (Lond.). 227:680-685.

31. Celis, J. E., B. Gesser, H. Holm Rasmussen, P. Madsen, H. Leffers, K. Dejgaard, B. Honore, E. Olsen, G. Ratz, J. B. Lauridsen, B. Basse, S. Mouritzen, M. Hellerup, A. Andersen, E. Walbum, A. Celis, G. Bauw, M. Puype, J. Van Damme, and J. Vandekerckhove. 1990. Comprehensive two-dimensional gel protein databases offer a global approach to the analysis of human cells: The transformed amnion cells (AMA) master database and its link to genome DNA sequence data. Electrophoresis. 11:989-1071.

32. Briand, P., and A. Lykkesfeldt. 1986. Long-term cultivation of a human breast cancer cell line, MCF-7, in a chemically defined medium. Effect of estradiol. Anticancer Res. 6:85-90.

33. Petersen, O. W., B. van Deurs, K. Vang Nielsen, M. W. Madsen, I. Laursen, I. Balslev, and P. Briand. 1990. Differential tumorigenecity of two autologous human breast carcinoma cell lines HMT-3909 S1 and HMT-3909 S8 established in serum-free medium. Cancer Res. 50:1-14.

34. Grinnell, F. 1994. Fibroblasts, myofibroblasts, and wound contraction. $J$. Cell Biol. 124:401-404.

35. Streuli, C. H., N. Bailey, and M. J. Bissell. 1991. Control of mammary epithelial differentiation: Basement membrane induces tissue-specific gene expression in the absence of cell-cell interaction and morphological polarity. J. Cell Biol. 115:1383-1395.

36. Schürch, W., T. A. Seemayer, and G. Gabbiani. 1992. Myofibroblast. In Histology for Pathologists. S. S. Sternberg, editor. Raven Press, Ltd., New York. 109-144.

37. Nehls, V., and D. Drenckhahn. 1991. Heterogeneity of microvascular pericytes for smooth muscle type alpha-actin. J. Cell Biol. 113:147-154.

38. Nehls, V., K. Denzer, and D. Drenckhahn. 1992. Pericyte involvement in capillary sprouting during angiogenesis in situ. Cell Tissue Res. 270:469-474.
39. Nehls, V., and D. Drenckhahn. 1993. The versatility of microvascular pericytes: from mesenchyme to smooth muscle? Histochemistry. 99:1-12.

40. Schlingemann, R. O., F. J. R. Reitveld, R. M. W. de Waal, S. Ferrone, and D. J. Ruiter. 1990. Expression of the high molecular weight melanomaassociated antigen by pericytes during angiogenesis in tumors and in healing wounds. Am. J. Pathol. 136:1393-1405.

41. Celis, J. E., P. Madsen, H. H. Rasmussen, H. Leffers, B. Honoré, B. Gesser, K. Dejgaard, E. Olsen, N. Magnusson, J. Kiil, et al. 1991. A comprehensive twodimensional gel protein database of noncultured unfractionated normal human epidermal keratinocytes: towards an integrated approach to the study of cell proliferation, differentiation and skin diseases. Electrophoresis. 12:802-872.

42. Chiquet-Ehrismann, R., P. Kalla, and C. A. Pearson. 1989. Participation of tenascin and transforming growth factor- $\beta$ in reciprocal epithelial-mesenchymal interactions of MCF7 cells and fibroblasts. Cancer Res. 49:4322-4325.

43. Schmitt-Gräff, A., H. Pau, R. Spahr, H. M. Piper, O. Skalli, and G. Gabbiani. 1990. Appearance of alpha-smooth muscle actin in human eye lens cells of anterior capsular cataract and in cultured bovine lens-forming cells. Differentiation. 43:115-122.

44. Desmoulière, A., L. Rubbia-Brandt, A. Abdiu, T. Walz, A. MacieiraCoelho, and G. Gabbiani. 1992. $\alpha$-Smooth muscle actin is expressed in a subpopulation of cultured and cloned fibroblasts and is modulated by $\gamma$-interferon. Exp. Cell Res. 201:64-73.

45. Doane, K. J., and D. E. Birk. 1991. Fibroblasts retain their tissue phenotype when grown in three-dimensional collagen gels. Exp. Cell Res. 195:432-442.

46. Buoro, S., P. Ferrarese, A. Chiavegato, M. Roelofs, M. Scatena, P. Pauletto, G. Passerini-Glazel, S. Pagano, and S. Sartore. 1993. Myofibroblast-derived smooth muscle cells during remodelling of rabbit urinary bladder wall induced by partial outflow obstruction. Lab. Invest. 69:589-602.

47. Chiavegato, A., M. Scatena, M. Roelofs, P. Ferrarese, P. Pauletto, G. Passerini-Glazel, F. Pagano, and S. Sartore. 1993. Cytoskeletal and cytocontractile protein composition of smooth muscle cells in developing and obstructed rabbit bladder. Exp. Cell Res. 207:310-320.

48. Roskelley, C. D., O. W. Petersen, and M. J. Bissell. 1993. The significance of the extracellular matrix in mammary epithelial carcinogenesis. In Advances in Molecular and Cell Biology. Jai Press, Inc., Greenwich, CT. 7:89-113.

49. Lin, C. Q., and M. J. Bissell. 1993. Multi-faceted regulation of cell differentiation by extracellular matrix. FASEB (Fed. Am. Soc. Exp. Biol.) J. 7:737743.

50. Petersen, O. W., L. Rønnov-Jessen, A. R. Howlett, and M. J. Bissell. 1992. Interaction with basement membrane serves to rapidly distinguish growth and differentiation pattern of normal and malignant human breast epithelial cells. Proc. Natl. Acad. Sci. USA. 89:9064-9068.

51. Schürch, W., T. A. Seemayer, and R. Lagacé. 1981. Stromal myofibroblasts in primary invasive and metastatic carcinomas. Virchows Arch. A Pathol. Anal. 391:125-139.

52. Duband, J.-L., A. M. Belkin, J. Syfrig, J. P. Thiery, and V. E. Kotelianski. 1992. Expression of $\alpha 1$-integrin, a laminin-collagen receptor, during myogenesis and neurogenesis in the avian embryo. Development (Camb.). 116:585-600.

53. Arteaga, C. L., J. Coffey, R. J., T. C. Dugger, C. M. McCutchen, H. L. Moses, and R. M. Lyons. 1990. Growth stimulation of human breast cancer cells with anti-transforming growth factor $\beta$ antibodies: Evidence for negative autocrine regulation by transforming growth factor $\beta$. Cell Growth \& Differ. 1:367-374.

54. Lyons, R. M., J. Keski-Oja, and H. L. Moses. 1988. Proteolytic activation of latent transforming growth factor- $\beta$ from fibroblast conditioned medium. $J$. Cell Biol. 106:1659-1665.

55. Vukicevic, S., H. K. Kleinman, F. P. Luyten, A. B. Roberts, N. S. Roche, and A. H. Reddi. 1992. Identification of multiple active growth factors in basement membrane matrigel suggests caution in interpretation of cellular activity related to extracellular matrix components. Exp. Cell Res. 202:1-8.

56. Basset, P., J. P. Bellocq, C. Wolf, I. Stoll, P. Hutin, J. M. Limacher, O. L. Podhajcer, M. P. Chenard, M. C. Rio, and P. Chambon. 1990. A novel metalloproteinase gene specifically expressed in stromal cells of breast carcinomas. Nature (Lond.). 348:699-704.

57. Pyke, C., P. Kristensen, E. Ralf kiaer, J. Grøndahl-Hansen, J. Eriksen, F. Blasi, and K. Danø. 1991. Urokinase-type plasminogen activator is expressed in stromal cells and its receptor in cancer cells at invasive foci in human colon adenocarcinomas. Am. J. Pathol. 138:1059-1067.

58. Blasi, F. 1993. Urokinase and urokinase receptor: a paracrine/autocrine system regulating cell migration and invasiveness. BioEssays. 15:105-111.

59. Odekon, L. E., F. Blasi, and D. B. Rifkin. 1994. Requirement for receptorbound urokinase in plasmin-dependent cellular conversion of latent TGF- $\beta$ to TGF- $\beta$. J. Cell. Physiol. 158:398-407.

60. Benzonana, G., O. Skalli, and G. Gabbiani. 1988. Correlation between the distribution of smooth muscle or non muscle myosins and $\alpha$-smooth muscle actin in normal and pathological soft tissues. Cell Motil. Cytoskeleton. 11:260-274.

61. Barsky, S. H., C. N. Roa, G. R. Grotendorst, and L. A. Liotta. 1982. Increased content of type $\mathrm{V}$ collagen in desmoplasia of human breast carcinoma. Am. J. Pathol. 108:276-283.

62. Krishnan, R., and E. G. Cleary. 1990. Elastin gene expression in elastotic human breast cancers and epithelial cell lines. Cancer Res. 50:2164-2171. 
63. Bissell, M. J. 1981. The differentiated state of normal and malignant cells or how to define a "normal" cell in culture. Int. Rev. Cytol. 70:27-100.

64. Blau, H. M., and D. Baltimore. 1991. Differentiation requires continuous regulation. J. Cell Biol. 112:781-783.

65. Weintraub, H., R. Davis, S. Tapscott, M. Thayer, M. Krause, R. Benezra T. K. Blackwell, D. Turner, R. Rupp, S. Hollenberg, Y. Zhuang, and A. Lassar. 1991. The myoD gene family: nodal point during specification of the muscle cell lineage. Science (Wash. DC). 251:761-766.

66. Watt, F. A. 1991. Cell culture models of differentiation. FASEB (Fed. Am. Soc. Exp. Biol.) J. 5:287-294.

67. Horgan, K., D. L. Jones, and R. E. Mansel. 1987. Mitogenicity of human fibroblasts in vivo for human breast cancer cells. Br. J. Surg. 74:227-229.

68. Mukaida, H., N. Hirabayashi, T. Hirai, T. Iwata, S. Saeki, and T. Toge. 1991. Significance of freshly cultured fibroblasts from different tissues in promoting cancer cell growth. Int. J. Cancer. 48:423-427.

69. Fabra, A., M. Nakajima, C. D. Bucana, and I. J. Fidler. 1992. Modulation of the invasive phenotype of human colon carcinoma cells by organ specific fibroblasts of nude mice. Differentiation (Camb.). 52:101-110.
70. Dimanche-Boitrel, M. T., L. Vakaet, P. Pujuguet, B. Chauffert, M. S. Martin, A. Hammann, F. van Roy, M. Mareel, and F. Martin. 1994. In vivo and in vitro invasiveness of a rat colon-cancer cell line maintaining E-cadherin expression: an enhancing role of tumor-associated myofibroblasts. Int. J. Cancer. 56:512-521.

71. Sieweke, M. H., N. L. Thompson, M. B. Sporn, and M. J. Bissell. 1990. Mediation of wound-related Rous Sarcoma Virus tumorigenesis by TGF- $\beta$. Science (Wash. DC). 248:1656-1660.

72. Arteaga, C. L., S. D. Hurd, A. R. Winnier, M. D. Johnson, B. M. Fendly, and J. T. Forbes. 1993. Anti-transforming growth factor (TGF) $-\beta$ antibodies inhibit breast cancer cells tumorigenicity and increase mouse spleen natural killer cell activity. J. Clin. Invest. 92:2569-2576.

73. Sieweke, M. H., and M. J. Bissell. 1994. The tumor promoting effect of wounding: a possible role for TGF- $\beta$-induced stromal alterations. Crit. Rev. Oncol./Hematol. In press.

74. Barsky, S. H., and R. Gopalakrishna. 1987. Increased invasion and spontaneous metastasis of B16 melanoma with inhibition of the desmoplastic response in C57 BL/6 mice. Cancer Res. 47:1663-1667. 